\title{
Editorial:
}

\section{E-Health: Accessing Knowledge for Global Health}

\author{
Patricia Abbott* \\ Johns Hopkins Schools of Nursing and Medicine \\ Johns Hopkins University \\ 525 North Wolfe St, Suite 414, Baltimore, MD 21205, USA \\ E-mail: pabbott2@son.jhmi.edu
}

*Corresponding author

\begin{abstract}
Globalization and information and communication technology (ICT) continues to change us and the world we live in, particularly when one considers the influence of ICT on health (e-health). The barriers that have contributed in the past to the inaccessibility of vital health information (and the experience needed to transform such data into actionable knowledge) are beginning to dissipate. Worldwide growth of telecommunications, a groundswell of technology savvy populations, and the dawning awareness of the power of digital health information are fundamentally altering the face of global health. As Thomas Friedman writes, ICT has made everyone a virtual next-door-neighbor, has "flattened" the world, leveled the playing field, and has enabled the exchange data and services from even the most remote locales around the globe. ICT in health is a global game-changer.
\end{abstract}

Keywords: Information and Communication Technology (ICT), e-Health, Globalization, Health Information.

Biographical notes: Patricia Abbott, $\mathrm{PhD}, \mathrm{RN}, \mathrm{FAAN}$ is an Associate Professor and Co-Director of the Johns Hopkins School of Nursing WHO Collaborating Center.

\section{Introduction}

Globalization and information and communication technology (ICT) continues to change us and the world we live in, particularly when one considers the influence of ICT on health (e-health). The barriers that have contributed in the past to the inaccessibility of vital health information (and the experience needed to transform such data into actionable knowledge) are beginning to dissipate. Worldwide growth of telecommunications, a groundswell of technology savvy populations, and the dawning awareness of the power of digital health information are fundamentally altering the face of global health. As Thomas Friedman writes, ICT has made everyone a virtual next-door-neighbor, has "flattened" the world, leveled the playing field, and has enabled the exchange data and services from even the most remote locales around the globe (Friedman, 2005). ICT in health is a global game-changer.

As e-health gains momentum, new avenues for the improvement of population and personal health are opening. Information asymmetries are reduced as health information once stacked in restrictive silos begins to flow into homes and communities. 
The sharing of new discoveries, dissemination of best practices, and tapping into the collective intelligence of dispersed, yet connected health practitioners are common sideeffects of e-health. Deaton speaks directly to this point, making the connection between knowledge exchange and improved health. "The health and life expectancy of the vast majority of mankind, whether they live in rich or poor countries, depends on ideas, techniques, and therapies developed elsewhere, so that it is the spread of knowledge that is the fundamental determinant of population health" (Deaton, 2004).

E-health and the ability to access knowledge resources to improve health are not limited to professionals and Westernized nations. Wireless communication techniques have spurred innovation in the health sector, particularly in Africa and Asia where the growth of cellular telephony has exploded. Increasingly, "connected" patients are using e-health methods to self-educate about health issues instead of relying upon providers to relay such information. The use of Short Messaging Service (SMS or "texting") via cell phones is finding new applications in health such as targeted delivery of health information. Isolation and inaccessibility of educational opportunities in remote areas, frequently cited as contributors to health professional outmigration, are being relieved by innovative uses of ICT. One only needs to study the work of the African Medical Research and Education Foundation (AMREF) and Accenture in Kenya to discover the potential that ICT holds in this regard.

Each of these examples point to the nascent potential of global e-health, however major challenges still remain. Affordability of access to communication networks is still prohibitive in many areas of the globe. Many societies find globalization and open information exchange as threatening to current ideologies and social structure; therefore restrictions to knowledge exchange and information sharing are often imposed. Liaw and Humphries (Liaw and Humphreys, 2006) have coined the term "the e-health paradox", to reflect these challenges: populations that may have the most to gain from e- health are those who are thwarted in their use due to barriers of untrained personnel, poor infrastructure, governmental restrictions, and lack of resources. The digital divide (or technological apartheid as it is sometimes called) continues to subvert the delivery of knowledge to areas of the globe that most desperately need it (Abbott and Coenen, 2008). Even in light of these persistent and significant challenges, the growth of e-health is expected to expand and the roadblocks will continue to dissipate.

\section{Introduction to this special issue}

This special issue aims to stimulate discussion and further application of ICT in global health. An overwhelming response to the call for papers illustrates the level of interest in this particular topic. Seven papers were chosen for publication in this edition representing but a small sample of the ongoing activity in the domain of "E-Health: Accessing Knowledge for Global Health". I would like to extend my appreciation to the Editor of the KM \& EL journal, Dr. Maggie Minhong Wang and those who served as reviewers for the articles received. My most heartfelt thanks go to Jonathan Martin, a colleague and pre-med student at Johns Hopkins who stepped in and reviewed many papers at a critical juncture. His assistance made this edition possible.

In the first paper by Spil, Schuring, Michel-Verkerke, Mugisha, \& Laggendijk (2010), differences in the diffusion of telehealth are examined by comparing case studies from Rwanda, Canada, Tanzania, and the Netherlands. Using the concepts of macro- and micro-relevance, and comparisons of the global north with the global south, interesting 
findings emerged. The relevance of telehealth technologies are rated highly where distances are long, or where distances are short but access to knowledge is difficult. These two aspects, micro and macro relevance, are useful concepts in understanding diffusion of innovation - in telehealth as described in this article - or other technological approaches that may be used for e-health.

Two articles in this issue are related to Virtual Communities of Practice (VCoPs), and the impact that these mechanisms can have on knowledge dissemination in health. O'Brien and Richey (2010) provide a comprehensive overview of V-CoPs and their use in reproductive health by the World Health Organization. These authors describe how the Implementing Best Practices in Reproductive Health Initiative (IBP) led by the WHO's Department of Reproductive Health and Research (WHO/RHR) and USAID has been used to close the knowledge to practice gap among public heath professionals working in family planning/reproductive health. The second work in VCoPs by Lori, Ortiz, Oyarzo, Abbott, and Land (2010) narrows the discussion of the IBP platform and VCoPs to focus upon the use in Nursing and Midwifery communities. Within the Global Alliance for Nursing and Midwifery (GANM) VCoP, several active sub-communities have emerged, including one dedicated to "Making Pregnancy Safer". A description of the formation of the community is provided, and interesting developments regarding a need to create English and Spanish versions of the VCoP are described. The challenges and rewards are presented, and the results of bilingual discussions and knowledge exchange held by the Making Pregnancy Safer/Parteria Y Enfermeria para una Maternidad Segura communities are discussed. The results from both of the VCoP papers illustrate the value of low-bandwidth communication networks for education, knowledge exchange and interaction.

Edenius, Keller, and Lindblad (2010) present the results of a qualitative casestudy approach undertaken to deepen the understanding of how knowledge can best be managed, across boundaries, in the face of innovation in practice. The discussions that differentiate between the syntactic, semantic, and pragmatic dimensions of knowledge transformation are intriguing and provide useful strategies for future applications. The authors present the use of a medical quality register, its impact upon standard practice patterns, and how innovation engendered by the register alters patient involvement.

The work by Chipps (2010) describes the implementation of two courses via teleeducation in KwaZulu-Natal, South Africa and the impact that this delivery mechanism has had on knowledge transfer. A review of the literature and the findings from her study demonstrate the effectiveness (in both cost and learning outcomes) from the use of this modality. A call for further application and research in this area is called for, especially when one considers the lack of skilled healthcare providers in parts of sub-Saharan Africa and the extreme need for the training of remote care-givers.

Chib, Lwin, Lee, Ng, and Wong (2010), from Singapore share their work on a game-based approach to HIV/AIDS education for adolescents. They proposed a conceptual framework based on the Extended Parallel Process Model (EPPM) and conducted an interesting study with Singapore adolescents. A primary implication suggested by the authors that originates from this work is that HIV/AIDS messages for adolescents should contain efficacy messages and that the messages must be specifically crafted for that specific age group. The point made by the authors is that prior HIV/AIDS messaging campaigns based on fear appeals have had little impact on adolescent beliefs. The use of gaming techniques when combined with efficacy messages is proposed as a more effective method of affecting behaviors in this critical age group according to the results of this interesting study. 
The final article by Blake and Kerr (2010) from Australia focuses upon digital sleep diaries, and their benefit in communication and exchange between patients and providers. This work is primarily descriptive in nature, and discusses the challenges in maintaining sleep diaries, the importance of the data contained within, and the benefits afforded by the creation of electronic methods of recording this type of data. The point is made that the exchange of more robust and comprehensive data about sleep patterns not only increases the knowledge base of the provider and contributes to the knowledge base of sleep disorders, but also has the potential to increase patient knowledge about, and involvement in, their own therapy.

Ultimately, what we learn from these articles is that the reach and the power of ehealth is just beginning to be realized. Creative minds from all over the globe are using ICT and e-health to challenge and change the current methods of global health provision, knowledge exchange, health monitoring, and assessment. As I reviewed these articles and marveled at the creativity, it reminded me of a quote from Henry Ford where he classified people with a creative bend as those with an "infinite capacity to not know what can't be done." After serving as guest editor for this special edition, I believe that I have come to know a group of authors who possess the exact same characteristics that Henry Ford described.

\section{References}

1 Abbott, P., \& Coenen, A. (2008). Globalization and advances in information and communication technologies: The impact on nursing and health. Nursing Outlook, 56(5), 238-246.

2 Blake, J., \& Kerr, D. (2010). Development of an online sleep diary for physician and patient use. Knowledge Management \& E-Learning: An International Journal, 2(2), 188-202.

3 Chib, A. I., Lwin, M. O., Lee, Z., Ng, V. W., \& Wong P. H. P. (2010). Learning AIDS in Singapore: Examining the effectiveness of HIV/AIDS efficacy messages for adolescents using ICTs. Knowledge Management \& E-Learning: An International Journal, 2(2), 169-187.

4 Chipps, J. (2010). The use of synchronous video-conference teaching to increase access to specialist nurse education in rural KwaZulu-Natal, South Africa. Knowledge Management \& E-Learning: An International Journal, 2(2), 154-168.

5 Deaton, T. (2004). Health in an Age of Globalization. Available online at: https://muse.jhu.edu/journals/brookings_trade_forum/v2004/2004.1deaton.pdf

6 Edenius, M., Keller, C., \& Lindblad, S. (2010). Managing knowledge across boundaries in healthcare when innovation is desired. Knowledge Management \& ELearning: An International Journal, 2(2), 134-153.

7 Friedman, T. (2005). The World is Flat: a Brief History of the Twenty-First Century. Farrar, Straus and Giroux, NY.

8 Liaw, S., \& Humphreys, J. (2006). Rural eHealth paradox: It's not just geography!. Australian Journal of Rural Health, 14, 95-98. 
9 Lori, J. R., Ortiz, D. D., Oyarzo, S., Abbott, P., \& Land, S. (2010). Developing Nursing and Midwifery Communities of Practice for Making Pregnancy Safer. Knowledge Management \& E-Learning: An International Journal, 2(2), 122-133.

10 O'Brien, M., \& Richey, C. (2010). Knowledge Networking for Family Planning: The Potential for Virtual Communities of Practice to Move Forward the Global Reproductive Health Agenda. Knowledge Management \& E-Learning: An International Journal, 2(2), 109-121.

11 Spil, T. A. M., Schuring, R. W., Mugisha, R., Michel-Verkerke, M. B., \& Lagendijk, P. J. B. (2010). The Relevance of Telehealth across the Digital Divide: The transfer of knowledge over distance. Knowledge Management \& E-Learning: An International Journal, 2(2), 89-108. 